\title{
Variação da temperatura do substrato e fotossíntese em mudas de laranjeira 'Valência'
}

\author{
José Rodrigues Magalhães Filho(1), Eduardo Caruso Machado(1), Daniela Favero São Pedro Machado(1), \\ Rômulo Augusto Ramos ${ }^{(1)}$ e Rafael Vasconcelos Ribeiro(1)
}

(1)Instituto Agronômico, Avenida Barão de Itapura, no 1.481, Botafogo, CEP 13012-970 Campinas, SP. E-mail: zeroagro@yahoo.com.br, danifavero@ yahoo.com.br, romuloiac@gmail.com, caruso@iac.sp.gov.br, rafael@iac.sp.gov.br

\begin{abstract}
Resumo - $\mathrm{O}$ objetivo deste trabalho foi avaliar a influência da temperatura do substrato nas trocas gasosas, atividade fotoquímica e relações hídricas, em plantas jovens de laranjeira 'Valência' enxertadas sobre limoeiro 'Cravo'. Foram utilizadas mudas com seis meses de idade. O experimento foi conduzido em câmara de crescimento, em que o substrato foi mantido a 10,20 (controle) ou $30^{\circ} \mathrm{C}$, e a temperatura do ar variou de 25 a $20^{\circ} \mathrm{C}$ entre o dia e a noite, com fotoperíodo de 12 horas e densidade de fluxo de fótons fotossinteticamente ativos de $800 \mu \mathrm{mol} \mathrm{m} \mathrm{m}^{-2} \mathrm{~s}^{-1}$. Mediu-se, em cada tratamento, a assimilação de $\mathrm{CO}_{2}$ em resposta à concentração de $\mathrm{CO}_{2}$ no mesofilo, a fluorescência da clorofila $a$ e o potencial da água na folha às $6 \mathrm{e}$ às $13 \mathrm{~h}$. A temperatura de $30^{\circ} \mathrm{C}$ promoveu aumento na assimilação de $\mathrm{CO}_{2}$, em razão de fatores difusivos e metabólicos, tendo-se observado aumento na eficiência máxima de carboxilação $\left(\mathrm{V}_{\mathrm{c} \text {, máx }}\right)$, na regeneração da ribulose-1,5-bisfosfato, $\left(\mathrm{J}_{\max }\right)$ e nas condutâncias estomática (gs) e do mesofilo (gi), em relação à temperatura controle. A menor temperatura causou aumento do dreno alternativo de elétrons e queda da assimilação de $\mathrm{CO}_{2}$, em consequência de limitações difusivas e metabólicas, evidenciadas por decréscimos em gs, gi, $\mathrm{V}_{c \text {, máx }}$ e $\mathrm{J}_{\text {máx }}$.
\end{abstract}

Termos para indexação: Citrus limonia, Citrus sinensis, fluorescência, relações hídricas, troca gasosa.

\section{Root temperature variation and photosynthesis of 'Valencia' sweet orange nursery trees}

\begin{abstract}
The aim of this work was to evaluate the influence of the substrate temperature on gas exchange, photochemical activity and water relations in 'Valencia' sweet orange grafted onto 'Rangpur' lime. Six-month-old nursery trees were used. The experiment was carried out in a growth chamber, where the root system was maintained at 10, 20 (control) or $30^{\circ} \mathrm{C}$, the air temperature varied between 25 and $20^{\circ} \mathrm{C}$ from day to night, the photoperiod and photosynthetic photon flux density were set to 12 hours and $800 \mu \mathrm{mol} \mathrm{m}^{-2} \mathrm{~s}^{-1}$, respectively. The $\mathrm{CO}_{2}$ assimilation rates in response to the intercellular $\mathrm{CO}_{2}$, chlorophyll $a$ fluorescence and leaf water potential at $6 \mathrm{~h}$ and $13 \mathrm{~h}$ were measured for each treatment. The higher root temperature increased the $\mathrm{CO}_{2}$ assimilation in relation to the control temperature, due to diffusive and metabolic factors: plants showed enhanced maximum carboxylation efficiency $\left(\mathrm{V}_{\mathrm{c}, \max }\right)$, ribulose-1,5-bisphosphate regeneration $\left(\mathrm{J}_{\max }\right)$, and both stomatal $(\mathrm{gs})$ and mesophyll (gi) conductances. The lowest root temperature led to increased alternative electron sink and decreased $\mathrm{CO}_{2}$ assimilation, due to diffusive and metabolic limitations, indicated by decreases in gs, gi, $\mathrm{V}_{\mathrm{c}, \max }$, and $\mathrm{J}_{\max }$.
\end{abstract}

Index therms: Citrus limonia, Citrus sinensis, fluorescence, water relations, gas exchange.

\section{Introdução}

O Estado de São Paulo é responsável por $86 \%$ da produção nacional de citros (FNP Consultoria \& Comércio, 2009), no entanto, a produtividade de suas lavouras é baixa, em torno de $22 \mathrm{Mg} \mathrm{ha}^{-1}$. O conhecimento de como as plantas respondem ao ambiente é importante para a compreensão do processo produtivo, pois permite que se desenvolvam técnicas de manejo para o aumento da produtividade.

As laranjeiras são árvores sempre verdes e mantêm sua capacidade fotossintetizante durante todo o ano.
Em decorrência dessa característica, as folhas são submetidas à variação estacional da disponibilidade de água, de radiação solar, de temperatura do ar e do solo. No decorrer de um ano, as variações no ambiente condicionam o desenvolvimento fenológico das plantas e causam alterações significativas nos processos fisiológicos (Ribeiro \& Machado, 2007).

A fotossíntese é a fonte primária dos carboidratos utilizados no crescimento e na manutenção da planta, e sua redução pode levar a decréscimos no crescimento e desenvolvimento e reduzir as reservas de carboidratos 
presentes nos diversos órgãos das plantas (Ribeiro \& Machado, 2007). A fotossíntese máxima em laranjeiras, nas condições climáticas do Estado de São Paulo, ocorre na primavera e no verão, estações mais quentes e úmidas, e decai progressivamente até alcançar valores mínimos nos meses de inverno, frios e secos. A produção fotossintética diária, em um dia claro de verão, chega a ser 2,9 vezes maior que a do inverno (Machado et al., 2002; Ribeiro \& Machado, 2007; Ribeiro et al., 2009). Sob condições de disponibilidade hídrica adequada, as causas da variação da fotossíntese, ao longo do ano, estão relacionadas a variações das temperaturas do ar e do solo, ao comprimento do dia e à fase de desenvolvimento da planta (Ribeiro \& Machado, 2007). Ribeiro et al. (2009), em experimento com laranjeiras jovens cultivadas em vaso, observaram que o decréscimo da fotossíntese no inverno, em relação ao verão, é consequência da redução das temperaturas do solo em conjunto com baixas temperaturas noturnas do ar, que causariam decréscimo da condutância estomática na eficiência de carboxilação da rubisco e na regeneração de ribulose-1,5-bisfosfato, em consequência do transporte de elétrons (Ribeiro et al., 2009).

A distribuição temporal e espacial da temperatura do solo, em um laranjal, varia entre 9 e $28^{\circ} \mathrm{C}$ do inverno ao verão, nas profundidade entre 5 e $40 \mathrm{~cm}$ (Ribeiro, 2006). A variação do crescimento anual da parte aérea e das raízes em citros está relacionada com esta variação da temperatura do ar e do solo (Bevington \& Castle, 1985). A temperatura adequada do solo incrementa a divisão celular, o que resulta em maior crescimento das raízes, e afeta a condutividade hidráulica e a permeabilidade de membranas (Dodd et al., 2000). Essas respostas das raízes à temperatura do solo afetam as relações hídricas e, possivelmente, a fotossíntese em laranjeiras.

No Brasil, alguns trabalhos foram realizados sobre o efeito do ambiente na fotossíntese de diversas cultivares de laranjeiras (Machado et al., 2002, 2005; Habermann et al., 2003; Ribeiro et al., 2009). Entretanto, pesquisas relacionadas ao efeito da temperatura do solo na região do sistema radicular sobre a fotossíntese e relações hídricas em laranjeiras não foram encontradas.

O objetivo deste trabalho foi avaliar os efeitos da variação da temperatura do substrato, na fotossíntese de mudas de laranjeira 'Valência' enxertadas em limoeiro 'Cravo'.

\section{Material e Métodos}

Foram utilizadas mudas de laranjeira 'Valência' [Citrus sinensis (L.) Osbeck] enxertada em limoeiro 'Cravo' [Citrus limonia (L.) Osbeck] com seis meses de idade, plantadas em sacolas de plástico perfuradas, com capacidade de $5 \mathrm{dm}^{3}$, preenchidas com substrato com 95\% de casca de Pinus e 5\% de vermiculita. As mudas foram irrigadas diariamente e receberam $400 \mathrm{~cm}^{3}$ de solução nutritiva diluída $\left(10 \mathrm{~cm}^{3}\right.$ de solução estoque por litro de água), a cada sete dias. A solução estoque constituiu-se de: $80 \mathrm{~g} \mathrm{dm}^{-3}$ de $\mathrm{Ca}\left(\mathrm{NO}_{3}\right)_{2}, 33,2 \mathrm{~g} \mathrm{dm}^{-3}$ de $\mathrm{Mg}\left(\mathrm{NO}_{3}\right)_{2}, 0,18 \mathrm{~g} \mathrm{dm}^{-3}$ de $\mathrm{MnSO}_{4}, 0,11 \mathrm{~g} \mathrm{dm}^{-3}$ de $\mathrm{ZnSO}_{4}$, 1,54 $\mathrm{g} \mathrm{dm}^{-3}$ de Fe EDTA, 5,58 $\mathrm{g} \mathrm{dm}^{-3}$ de $\mathrm{Cu}$ EDTA, $36 \mathrm{~g} \mathrm{dm}^{-3}$ de $\mathrm{KNO}_{3}, 8 \mathrm{~g} \mathrm{dm}^{-3}$ de $\mathrm{NH}_{4} \mathrm{H}_{2} \mathrm{PO}_{4}$, $12 \mathrm{~g} \mathrm{dm}^{-3}$ de $\mathrm{K}_{2} \mathrm{SO}_{4}, 1 \mathrm{~cm}^{3} \mathrm{dm}^{-3}$ de solução de $\mathrm{NaMoO}_{4}$.

$\mathrm{O}$ experimento foi conduzido em câmara de crescimento (PGR14, Conviron, Canadá), em que a temperatura do ar (diurna/noturna) manteve-se a $25 \pm 1 / 20 \pm 1^{\circ} \mathrm{C}$, o fotoperíodo foi de 12 horas, a densidade de fluxo de fótons fotossinteticamente ativos (DFFFA) foi ajustada para $800 \mu \mathrm{mol} \mathrm{m} \mathrm{m}^{-2} \mathrm{~s}^{-1}$, e o deficit de pressão de vapor do ar (DPV) esteve entre 1 e 1,5 $\mathrm{kPa}$.

Dentro da câmara de crescimento, foram dispostas três caixas de isopor, com cinco plantas por caixa. As caixas continham água a 10,20 e $30^{\circ} \mathrm{C}$, o que permitiu o controle da temperatura no substrato e no sistema radicular, independentemente da parte aérea. As temperaturas da água e do substrato foram monitoradas e registradas com termômetros, durante todo o período experimental. As sacolas com as plantas foram protegidas com sacos de plástico para evitar a hipoxia nas raízes. As plantas permaneceram por dez dias dentro da câmara de crescimento. No $1^{\circ}$ dia (dia 0), a temperatura da água nas três caixas foi de $20^{\circ} \mathrm{C}$, para a aclimatação das plantas. No início da noite seguinte, iniciou-se o tratamento com diferentes temperaturas, ou seja, a água de uma caixa foi resfriada para $10^{\circ} \mathrm{C}$, em outra caixa foi mantida a $20^{\circ} \mathrm{C}$ (controle), e a água da terceira caixa foi aquecida a $30^{\circ} \mathrm{C}$. Para o aquecimento e manutenção dos $30^{\circ} \mathrm{C}$, utilizou-se um aquecedor com termostato e, para o resfriamento e manutenção dos $10^{\circ} \mathrm{C}$, adicionavam-se cubos de gelo diariamente. Em todos os tratamentos, a temperatura variou, no máximo, em $1^{\circ} \mathrm{C}$. No tratamento controle $\left(20^{\circ} \mathrm{C}\right)$, a temperatura da água foi mantida naturalmente. Os substratos foram mantidos nessas temperaturas por cinco dias consecutivos (dia 1 até dia 5). Do sexto dia (6) até o nono dia (9), as plantas com substrato a 10 e a

Pesq. agropec. bras., Brasília, v.44, n.9, p.1118-1126, set. 2009 
$30^{\circ} \mathrm{C}$ retornaram às condições iniciais, ou seja, a $20^{\circ} \mathrm{C}$ para se avaliar a recuperação das plantas.

As medidas das trocas gasosas e da atividade fotoquímica foram realizadas simultaneamente, tendo-se utilizado um analisador portátil de fotossíntese com fluorômetro acoplado (Li-6400, acoplado com câmara de fluorescência 6400-40, Licor, Lincoln, USA), em folhas totalmente expandidas, com aproximadamente dois meses. As variáveis de trocas gasosas foram: assimilação de $\mathrm{CO}_{2}\left(\mathrm{~A}, \mu \mathrm{mol} \mathrm{m} \mathrm{m}^{-2} \mathrm{~s}^{-1}\right)$, condutância estomática $\left(\mathrm{gs}, \mathrm{mol} \mathrm{m}^{-2} \mathrm{~s}^{-1}\right)$ e concentração intercelular de $\mathrm{CO}_{2}\left(\mathrm{Ci}, \mu \mathrm{mol} \mathrm{mol}^{-1}\right)$. A assimilação bruta de $\mathrm{CO}_{2}$ foi calculada por $\mathrm{Ag}=\mathrm{A}+\mathrm{R}$, em que: $\mathrm{R}$ representa a respiração mitocondrial, medida antes do fim do período escuro. As medidas de fluorescência da clorofila $a$ foram realizadas pelo método do pulso de saturação (Maxwell \& Johnson, 2000), tendo-se utilizado a nomenclatura recomendada por Baker (2008). Em presença de luz, foi medida a fluorescência máxima $\left(\mathrm{F}_{\mathrm{m}}{ }^{\prime}\right)$, a fluorescência no estado de equilíbrio dinâmico $\left(\mathrm{F}^{\prime}\right)$, e a fluorescência mínima $\left(\mathrm{F}_{0}{ }^{\prime}\right)$, que permitiram o cálculo das seguintes variáveis (Baker, 2008): eficiência máxima do fotossistema II (PSII), em presença de luz $\left(\mathrm{F}_{\mathrm{v}}{ }^{\prime} / \mathrm{F}_{\mathrm{m}}{ }^{\prime}\right.$, em que $\left.\mathrm{F}_{\mathrm{v}}{ }^{\prime}=\mathrm{F}_{\mathrm{m}}{ }^{\prime}-\mathrm{F}_{0}{ }^{\prime}\right)$; eficiência operacional do PSII $\left(\mathrm{F}_{\mathrm{q}}{ }^{\prime} / \mathrm{F}_{\mathrm{m}}{ }^{\prime}\right.$, em que $\left.\mathrm{F}_{\mathrm{q}}{ }^{\prime}=\mathrm{F}_{\mathrm{m}}{ }^{\prime}-\mathrm{F}^{\prime}\right)$; fator de eficiência do PSII $\left(\mathrm{F}_{\mathrm{q}}{ }^{\prime} / \mathrm{F}_{\mathrm{v}}{ }^{\prime}\right)$; coeficiente de extinção não fotoquímica $\left[\mathrm{NPQ}=\left(\mathrm{F}_{\mathrm{m}}-\mathrm{F}_{\mathrm{m}}{ }^{\prime}\right) / \mathrm{F}_{\mathrm{m}}{ }^{\prime}\right]$; e transporte aparente de elétrons $\left[\mathrm{ETR}=\left(\mathrm{DFFFA} \times \mathrm{F}_{\mathrm{q}}{ }^{\prime}\right.\right.$ / $\left.\left.\mathrm{F}_{\mathrm{m}}{ }^{\prime} \times 0,5 \times 0,84\right)\right]$, conforme Schreiber et al. (1998). Para o cálculo do transporte aparente de elétrons (ETR), a fração de excitação de energia distribuída para o PSII foi considerada 0,5 e a fração de DFFFA absorvida pela folha foi 0,84 (Demmig \& Björkman, 1987). A relação ETR/Ag foi utilizada para estimativa do dreno alternativo de elétrons (Ribeiro et al., 2009). A eficiência quântica máxima do PSII $\left(\mathrm{F}_{\mathrm{v}} / \mathrm{F}_{\mathrm{m}}\right.$, em que $\mathrm{F}_{\mathrm{v}}=\mathrm{F}_{\mathrm{m}}-\mathrm{F}_{0}$ ) foi calculada a partir de medidas de fluorescência máxima $\left(\mathrm{F}_{\mathrm{m}}\right)$ e mínima $\left(\mathrm{F}_{0}\right)$, em folhas adaptadas ao escuro (por uma noite).

Foram ajustadas curvas diárias de assimilação de $\mathrm{CO}_{2}$, em função da concentração intercelular de $\mathrm{CO}_{2}$ (A/Ci), sob DFFFA de $1.200 \mu \mathrm{mol} \mathrm{m} \mathrm{m}^{-2} \mathrm{~s}^{-1}$. A variação de $\mathrm{Ci}$ foi obtida pelo controle da concentração de $\mathrm{CO}_{2}$ do ar de entrada (referência), da câmara de medida do Li-6400 (Long \& Bernacchi, 2003). As concentrações

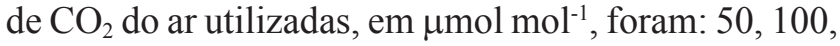
200, 300, 400, 600, 800, 1.000, 1.200, 1.400 e 1.600 . A partir dos valores de $\mathrm{Ci}$, calculou-se a concentração de $\mathrm{CO}_{2}$ no cloroplasto $(\mathrm{Cc})$, de acordo com modelo proposto por Epron et al. (1995), e ajustou-se a curva $\mathrm{A} / \mathrm{Cc}$. A curva $\mathrm{A} / \mathrm{Cc}$ foi utilizada para a estimativa da eficiência máxima de carboxilação $\left(\mathrm{V}_{\mathrm{c} \text {, máx }}\right)$ da ribulose-1,5-bisfostafo carboxilase/oxigenase (Rubisco) e para a regeneração máxima de ribulose-1,5-bisfosfato $(\mathrm{RuBP})$ dependente do transporte de elétrons ( $\left.\mathrm{J}_{\text {máx }}\right)$. O modelo de Farquhar de fotossíntese foliar foi ajustado à curva $\mathrm{A} / \mathrm{Cc}$ para calcular $\mathrm{V}_{\mathrm{c} \text {, máx }}$ e $\mathrm{J}_{\text {máx }}$ (Farquhar et al., 1980), pelo método do quadrado mínimo, no programa Origin 7.5 (OriginLab, 2008) . Os valores de ponto de compensação de $\mathrm{CO}_{2}$, na ausência de respiração diurna $\left(\Gamma^{*}\right)$, e as constantes de Michaelis-Menten para as atividades de carboxilação e oxigenação da Rubisco (Kc e Ko, respectivamente), em função da temperatura, foram calculados de acordo com Bernacchi et al. (2001). A condutância interna ou do mesofilo (gi) foi calculada segundo Epron et al. (1995); $g_{i}=A /\left(C_{i}-C_{c}\right)$.

O potencial da água na folha (em $\mathrm{MPa}$ ) foi medido às $6 \mathrm{~h}\left(\Psi_{6 \mathrm{~h}}\right)$ e às $13 \mathrm{~h}\left(\Psi_{13 \mathrm{~h}}\right)$, com câmara de pressão (modelo 3005, Soil Moisture Equipment, EUA), segundo Kaufmann (1968). A condutividade hidráulica $\left(\mathrm{K}_{\mathrm{L}}, \mathrm{mmol} \mathrm{m}^{-2} \mathrm{~s}^{-1} \mathrm{MPa}^{-1}\right)$ foi estimada segundo método proposto por Hubbard et al. (2001).

Utilizou-se o delineamento experimental em parcelas inteiramente casualizadas e subdivididas no tempo, com cinco repetições, tendo-se os tratamentos (três temperaturas) como parcelas e o tempo (cinco dias de avaliação) como subparcelas. Os dados foram submetidos à análise de variância (ANOVA), e as médias foram comparadas pelo teste de Tukey, a 5\% de probabilidade.

\section{Resultados e Discussão}

Após o primeiro dia de tratamento das raízes, a temperatura afetou significativamente a fotossíntese $(p<0,05)$. Houve acréscimo de 33 a $67 \%$ na assimilação de $\mathrm{CO}_{2}$ (A) entre o $1^{\circ}$ e o $5^{\circ}$ dias, nas plantas em que a temperatura do substrato passou de 20 para $30^{\circ} \mathrm{C}$, enquanto naquelas em que a temperatura foi reduzida de 20 para $10^{\circ} \mathrm{C}$, ocorreu decréscimo de $33 \%$ no mesmo período (Figura $1 \mathrm{~A}$ ). Essa resposta à temperatura está relacionada, em parte, a fatores difusivos, indicados pelo aumento, em relação ao controle $\left(20^{\circ} \mathrm{C}\right)$, da condutância estomática (gs) e da condutância do mesofilo (gi), no tratamento a $30^{\circ} \mathrm{C}$, e pela redução dessas variáveis no tratamento a $10^{\circ} \mathrm{C}$ (Figura $1 \mathrm{C} \mathrm{e} \mathrm{D).} \mathrm{Vários} \mathrm{fatores} \mathrm{estão}$ 
relacionados à abertura ou fechamento dos estômatos (Allen \& Ort, 2001; Machado et al., 2002, 2005). Um dos fatores que pode ter induzido maior gs no tratamento a $30^{\circ} \mathrm{C}$ foi a menor concentração de $\mathrm{CO}_{2}$ na câmara subestomática (Figura $1 \mathrm{~B}$ ), em consequência do maior consumo pela fixação de $\mathrm{CO}_{2}$ e pela maior difusão do $\mathrm{CO}_{2}$ nas células do mesofilo, indicado pelos maiores valores de gi (Figura $1 \mathrm{D}$ ). Outro fator que pode afetar gs é o potencial da água na folha (Habermann et al., 2003). De fato, observou-se que há relação entre a diminuição da temperatura das raízes e a queda no potencial de água nas folhas às $13 \mathrm{~h}\left(\Psi_{13 \mathrm{~h}}\right)$ e gs (Figuras $1 \mathrm{C}$ e $\left.2 \mathrm{~B}\right)$. O potencial de água nas folhas, às $6 \mathrm{~h}\left(\Psi_{6 \mathrm{~h}}\right)$, não apresentou diferença entre os tratamentos, e os valores encontrados, em torno de $-0,15 \mathrm{MPa}$, indicaram que os substratos estavam com boa disponibilidade hídrica (Figura $2 \mathrm{~A}$ ).
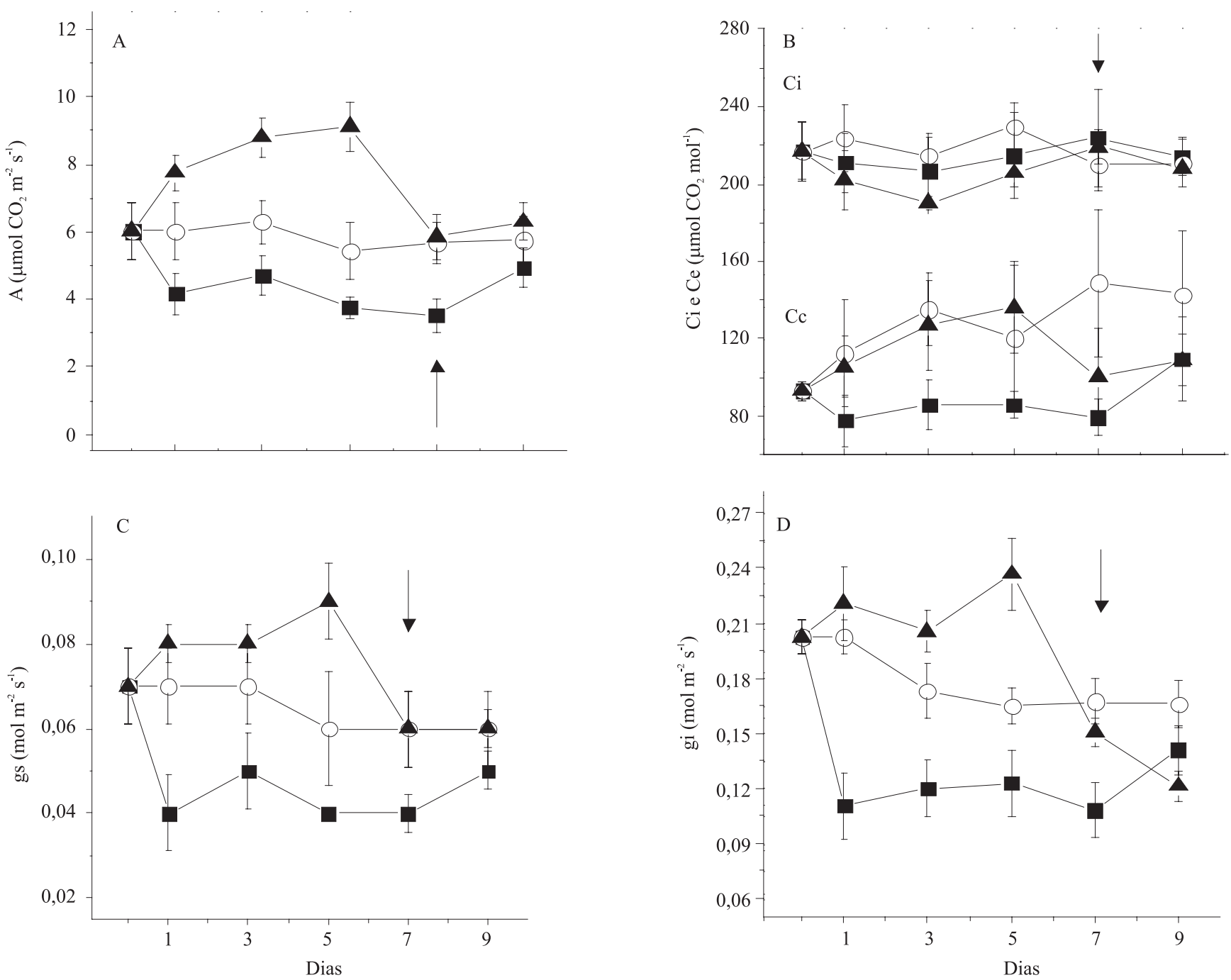

$-10^{\circ} \mathrm{C} \quad-\quad 20^{\circ} \mathrm{C} \quad \boldsymbol{\Delta} 30^{\circ} \mathrm{C}$

Figura 1. Efeito da temperatura do substrato sobre: $\mathrm{A}$, assimilação de $\mathrm{CO}_{2}(\mathrm{~A})$; $\mathrm{B}$, concentração intercelular (Ci) e no cloroplasto $(\mathrm{Cc})$ de $\mathrm{CO}_{2} ; \mathrm{C}$, na condutância estomática (gs); e D, condutância do mesofilo (gi), em mudas de laranjeira 'Valência' enxertadas em limoeiro 'Cravo' . Medidas realizadas sob densidade de fluxo de fótons fotossinteticamente ativos de $1.200 \mu \mathrm{mol} \mathrm{m} \mathrm{m}^{-2}$, temperatura do ar dia/noite $25 / 20^{\circ} \mathrm{C}$, e concentração de $\mathrm{CO}_{2}$ ambiente constante de $380 \mu \mathrm{mol} \mathrm{mol}{ }^{-1}$. No dia 0 , todas as plantas com temperatura de raízes de $20^{\circ} \mathrm{C}$; dias 1 a 5 , tratamento com temperaturas de 10,20 e $30^{\circ} \mathrm{C}$; dias 6 a 9 , período de recuperação com temperatura de $20^{\circ} \mathrm{C}$. Cada ponto representa a média de cinco repetições \pm desvio-padrão. Setas indicam o início da realização das medidas no período de recuperação. 

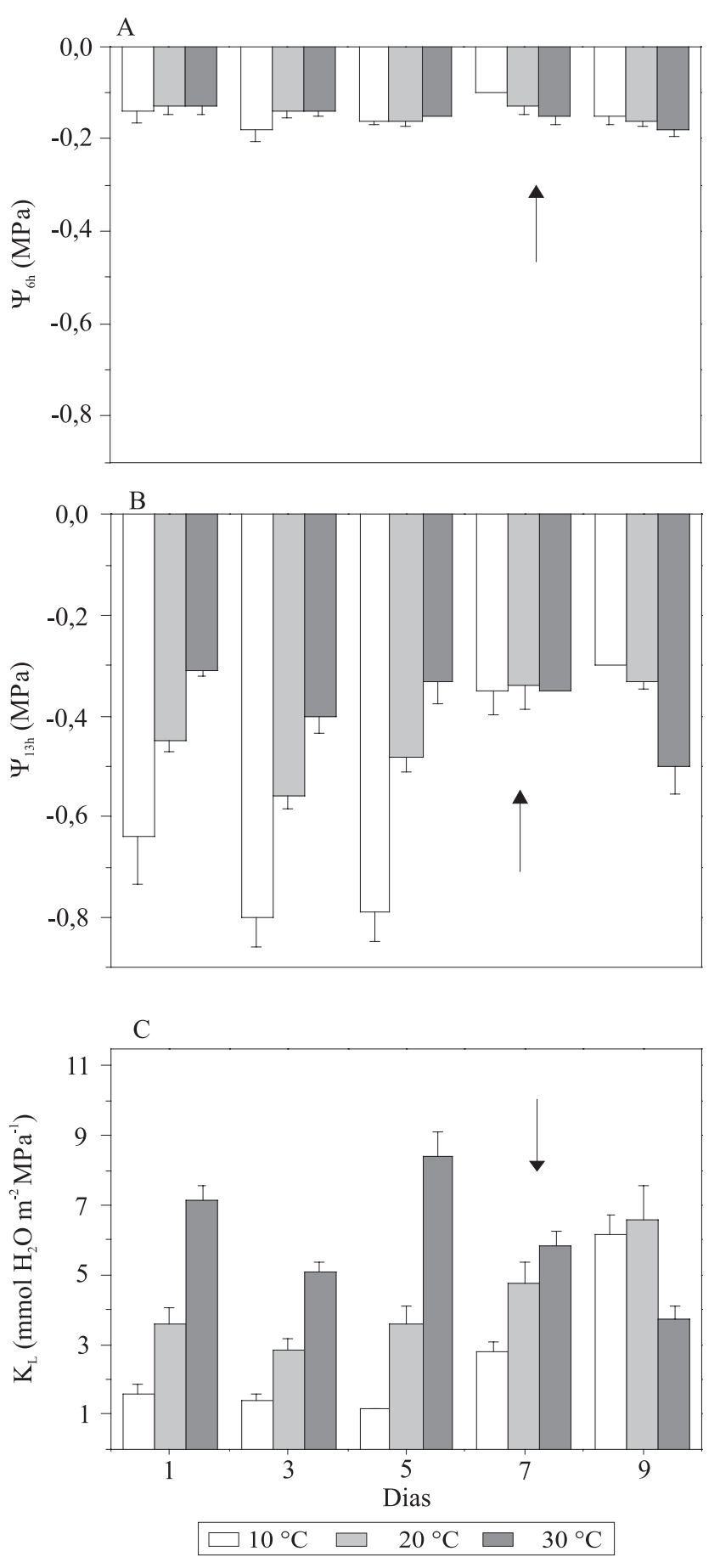

Figura 2. Efeito da temperatura do substrato sobre: A, potencial da água na folha às $6 \mathrm{~h}\left(\Psi_{6 \mathrm{~h}}\right) ; \mathrm{B}$, potencial da água na folha às $13 \mathrm{~h}\left(\Psi_{13 \mathrm{~h}}\right) ; \mathrm{C}$, condutividade hidráulica $\left(\mathrm{K}_{\mathrm{L}}\right)$, em mudas de laranjeira 'Valência' enxertadas em limoeiro 'Cravo'. Dias 1 a 5, tratamento com temperatura das raízes de 10,20 ou $30^{\circ} \mathrm{C}$; dias 6 a 9 , período de recuperação com temperatura de $20^{\circ} \mathrm{C}$. Cada barra representa a média de cinco repetições \pm desvio-padrão. Setas indicam o início da realização das medidas no período de recuperação.
O potencial de água na folha está relacionado à capacidade de reposição da água perdida pela transpiração; a facilidade do transporte da água na planta é quantificada pela condutividade hidráulica $\left(\mathrm{K}_{\mathrm{L}}\right)$. O maior valor de $\mathrm{K}_{\mathrm{L}}$, no tratamento a $30^{\circ} \mathrm{C}$, em relação aos outros dois tratamentos (Figura $2 \mathrm{C}$ ), possibilitou maior hidratação dos tecidos foliares e manteve maior $\Psi_{13 \mathrm{~h}}$. Nas plantas com substrato a $10^{\circ} \mathrm{C}$, o valor de $\mathrm{K}_{\mathrm{L}}$ no mesmo período foi, em média, quatro vezes menor do que o ocorrido a $30^{\circ} \mathrm{C}$ (Figura $2 \mathrm{C}$ ) e resultou em menor $\Psi_{13 \mathrm{~h}}$ (Figura $2 \mathrm{~B}$ ). A absorção de água nas raízes é mediada por canais de proteínas intrínsecas, presentes na membrana plasmática, denominadas aquaporinas. A atividade dessas proteínas parece comandar a absorção de água do solo, e elas são responsáveis pelo aumento ou redução da resistência ao fluxo da água na planta (Tournaire-Roux et al., 2003), de forma que também devem estar relacionadas com $\mathrm{K}_{\mathrm{L}}$. Assim, o resfriamento das raízes de 20 para $10^{\circ} \mathrm{C}$, possivelmente, reduziu a atividade das aquaporinas (redução significativa de $\mathrm{K}_{\mathrm{L}}$ ), a absorção de água pelas raízes e a reidratação das folhas, o que causou diminuição de gs e gi (Flexas et al., 2008; Warren, 2008) (Figuras 1 D e 2 C). No entanto, o aumento da temperatura do substrato de 20 para $30^{\circ} \mathrm{C}$ aumentaria a atividade das aquaporinas, e manteria elevada a absorção de água e o fluxo de $\mathrm{CO}_{2}$ no mesofilo foliar (Figura $1 \mathrm{D}$ ).

$\mathrm{O}$ retorno das temperaturas de 10 e $30^{\circ} \mathrm{C}$ para $20^{\circ} \mathrm{C}-$ período de recuperação -, a partir do sexto dia, induziu diferentes respostas entre os tratamentos nas variáveis analisadas. Nas plantas que tiveram as raízes resfriadas de 30 para $20^{\circ} \mathrm{C}$, os valores de A, Ci, gs, gi, $\Psi_{13 \mathrm{~h}}$ e $\mathrm{K}_{\mathrm{L}}$ diminuíram e retornaram aos valores iniciais do controle no dia seguinte (dia 7), o que mostra a rápida aclimatação das plantas à temperatura do substrato. Todavia, nas plantas que tiveram suas raízes aquecidas de 10 para $20^{\circ} \mathrm{C}$, o retorno daquelas variáveis aos valores iniciais só ocorreu no nono dia, ou seja, três dias após o retorno da temperatura do substrato (Figuras 1 e 2). Essa resposta indica que temperaturas mais baixas causam mudanças fisiológicas mais acentuadas em níveis celulares, e que é necessário tempo maior para serem revertidas.

A eficiência quântica fotoquímica máxima do PSII $\left(\mathrm{F}_{\mathrm{v}} / \mathrm{F}_{\mathrm{m}}\right)$ foi semelhante nos três tratamentos e variou entre 0,77 e 0,81 (Figura $3 \mathrm{~A}$ ). Esses valores 

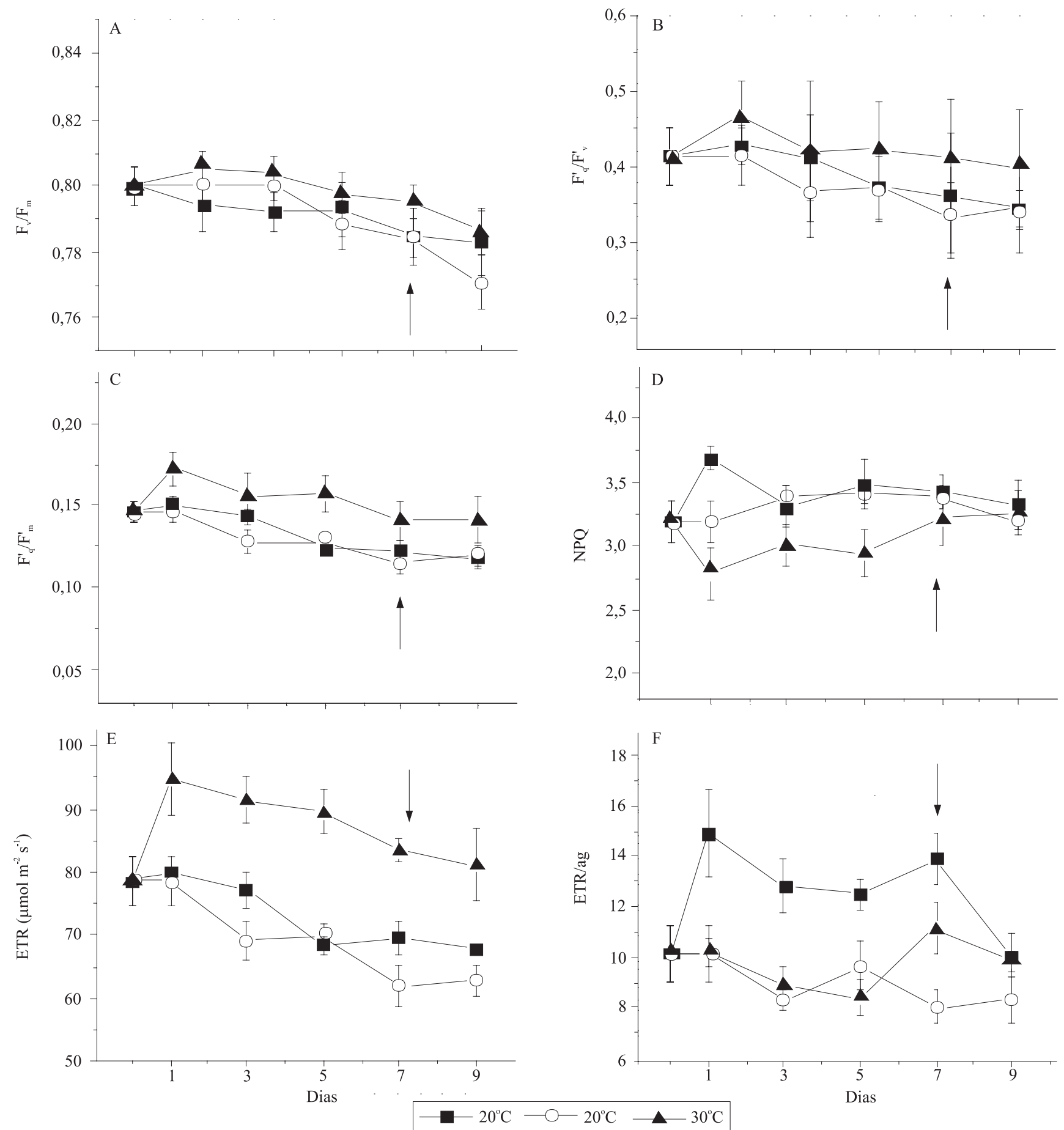

Figura 3. Efeito da temperatura do substrato sobre: A, eficiência quântica fotoquímica máxima do PSII (Fv/Fm); B, fator de eficiência do PSII $\left(\mathrm{F}_{\mathrm{q}}{ }^{\prime} / \mathrm{F}_{\mathrm{v}}{ }^{\prime}\right)$; C, eficiência quântica operacional do PSII $\left(\mathrm{F}_{\mathrm{q}}{ }^{\prime} / \mathrm{F}_{\mathrm{m}}{ }^{\prime}\right) ; \mathrm{D}$, coeficiente de extinção não fotoquímica (NPQ); E, transporte aparente de elétrons (ETR); F, relação entre a taxa de transporte de elétrons e a assimilação bruta de $\mathrm{CO}_{2}$ (ETR/Ag), em mudas de laranjeira 'Valência' enxertadas em limoeiro 'Cravo'. Medidas realizadas em densidade de fluxo de fótons fotossinteticamente ativos de $1.200 \mu \mathrm{mol} \mathrm{m}^{-2} \mathrm{~s}^{-1}$, temperatura do ar dia/noite a $25 / 20^{\circ} \mathrm{C}$, e concentração de $\mathrm{CO}_{2}$ ambiente constante a $380 \mu \mathrm{mol} \mathrm{mol}^{-1}$. Dia 0 , todas as plantas com temperatura de raízes de $20^{\circ} \mathrm{C}$; dias 1 a 5 , tratamento com temperaturas de 10,20 e $30^{\circ} \mathrm{C}$; dias 6 a 9 , período de recuperação com temperatura de $20^{\circ} \mathrm{C}$. Cada ponto representa a média de cinco repetições \pm desvio padrão. Setas indicam o início da realização das medidas no período de recuperação. 
indicam a ausência de fotoinibição, conforme também relatado por Ribeiro et al. (2009).

No tratamento a $30^{\circ} \mathrm{C}$, o fator de eficiência do PSII $\left(\mathrm{F}_{\mathrm{q}}{ }^{\prime} / \mathrm{F}_{\mathrm{v}}{ }^{\prime}\right)$ foi significativamente maior em relação aos tratamentos de 20 e $10^{\circ} \mathrm{C}$, que não diferiram entre si (Figura $3 \mathrm{~B}$ ). A maior fixação de $\mathrm{CO}_{2}$ a $30^{\circ} \mathrm{C}$ (Figura $1 \mathrm{~A}$ ) consumiu mais ATP e NADPH no ciclo de Calvin, assim, ocorreu maior taxa de oxidação das quinonas (Baker, 2008) e, portanto, maior eficiência operacional do PSII $\left(\mathrm{F}_{\mathrm{q}}{ }^{\prime} / \mathrm{F}_{\mathrm{m}}{ }^{\prime}\right)$ em relação aos outros tratamentos de 10 e $20^{\circ} \mathrm{C}$ (Figura $3 \mathrm{C}$ ). Com as raízes a $30^{\circ} \mathrm{C}$, a maior relação $\mathrm{F}_{\mathrm{q}}{ }^{\prime} / \mathrm{F}_{\mathrm{m}}{ }^{\prime}$ causou maior ETR (transporte aparente de elétrons), entre PSII e PSI, em relação aos demais tratamentos (Figura 3 E). Embora o valor de A seja maior no tratamento de raízes a $20^{\circ} \mathrm{C}$ em relação a $10^{\circ} \mathrm{C}$ (Figura $1 \mathrm{~A}$ ), o ETR foi semelhante entre eles. Esses resultados indicam maior dissipação de energia, pelo aumento do coeficiente de extinção não fotoquímica (NPQ), a 10 e $20^{\circ} \mathrm{C}$ (Figura 3 D), e da relação entre o transporte de elétrons e a assimilação bruta de $\mathrm{CO}_{2}(\mathrm{ETR} / \mathrm{Ag})$ para plantas com raízes a $10^{\circ} \mathrm{C}$
(Figura $3 \mathrm{~F}$ ). $\mathrm{O}$ aumento da ETR/Ag, no tratamento a $10^{\circ} \mathrm{C}$, indica aumento da dissipação de energia por drenos alternativos à fixação de $\mathrm{CO}_{2}$ (Baker, 2008). Maior ETR/Ag e NPQ são respostas protetoras contra a fotoinibição, já relatadas quanto aos citros (Medina et al., 2002; Ribeiro et al., 2009).

A partir do sexto dia, quando as raízes a $30^{\circ} \mathrm{C}$ retornaram para $20^{\circ} \mathrm{C}, \mathrm{A}$ decresceu (Figura $1 \mathrm{~A}$ ) sem a correspondente redução em ETR (Figura 3 E). Como consequência, houve aumento do consumo de elétrons por drenos alternativos, indicado pelo aumento $(p<0,05)$ de ETR/Ag (Figuras 1 A e 3 F). $\mathrm{O}$ retorno da temperatura das raízes de 10 para $20^{\circ} \mathrm{C}$ causou aumento de A e, consequentemente, queda na relação ETR/Ag, o que indica acréscimo na utilização de elétrons para fixação de $\mathrm{CO}_{2}$ (Figuras $1 \mathrm{~A}$ e $3 \mathrm{~F}$ ).

Em plantas cultivadas com temperatura do substrato a $10^{\circ} \mathrm{C}$ (dias 1 a 5$)$, houve decréscimo $(\mathrm{p}<0,05)$ de até $23 \%$ na eficiência máxima de carboxilação $\left(\mathrm{V}_{\mathrm{c} \text {, máx }}\right)$, em relação às temperaturas de 20 e $30^{\circ} \mathrm{C}$, que não diferiram entre si (Figura 4 A). A temperatura também afetou a

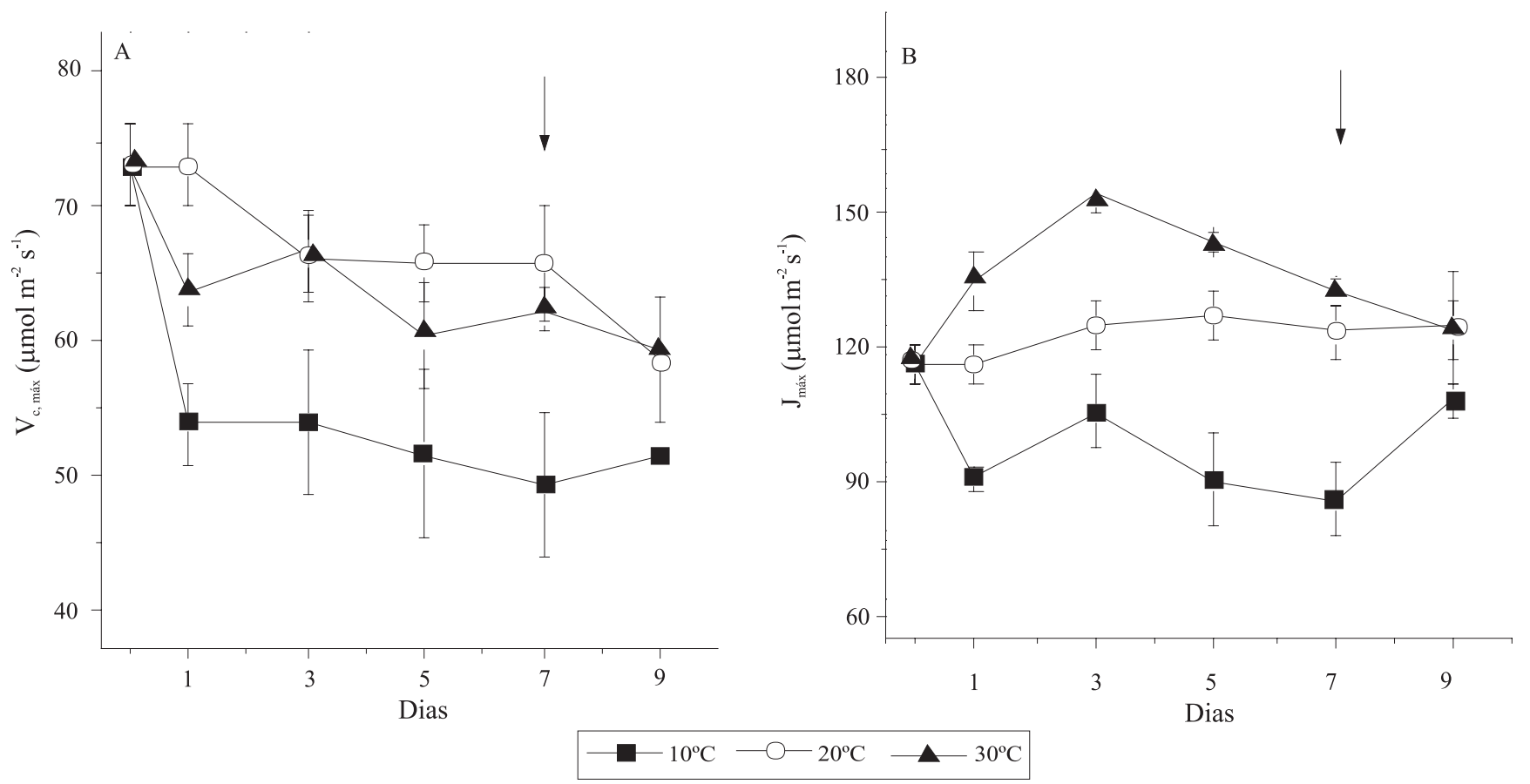

Figura 4. Efeito da temperatura do substrato sobre: $\mathrm{A}$, máxima carboxilação da Rubisco $\left(\mathrm{V}_{\mathrm{c}, \max }\right)$, $\mathrm{B}$, máxima regeneração da RuBP dependente do transporte de elétrons $\left(\mathrm{J}_{\text {máx }}\right)$, em mudas de laranjeira 'Valência' enxertadas em limoeiro 'Cravo'. Medidas realizadas entre $9 \mathrm{~h}$ e $16 \mathrm{~h}$, sob densidade de fluxo de fótons fotossinteticamente ativos de $1.200 \mu \mathrm{mol} \mathrm{m}^{-2} \mathrm{~s}^{-1}$. Dia 0 , todas as plantas com temperatura das raízes a $20^{\circ} \mathrm{C}$; dias 1 a 5 , tratamento com temperaturas a 10,20 ou $30^{\circ} \mathrm{C}$, dias 6 a 9 , período de recuperação com temperaturas a $20^{\circ} \mathrm{C}$. Cada ponto representa a média de cinco repetições \pm desvio-padrão. Setas indicam o início da realização das medidas no período de recuperação. 
regeneração da $\operatorname{RuBP}\left(\mathrm{J}_{\text {máx }}\right)$, com diferenças significativas entre os três tratamentos (Figura 4 B). Os maiores valores de $\mathrm{J}_{\text {máx }}$ ocorreram nas plantas com raízes a $30^{\circ} \mathrm{C}$ e diminuíram em consequência da queda da temperatura do substrato (Figura $4 \mathrm{~B}$ ). Estas duas variáveis $\mathrm{V}_{\mathrm{c} \text {, máx }} \mathrm{e} \mathrm{J}_{\text {máx }}$ indicaram que a temperatura mais elevada proporcionou melhores condições de assimilação de $\mathrm{CO}_{2}$ (Figura $1 \mathrm{~A}$ ), em razão de fatores relacionados aos processos bioquímicos da fotossíntese.

Zhou et al. (2007) observaram, em Curcubitaceae, que o resfriamento das raízes de 14 para $7^{\circ} \mathrm{C}$ causou decréscimo de $\mathrm{A}$, de $\mathrm{V}_{\mathrm{c} \text {, máx }}$ e do teor de citocinina. Esses autores sugeriram que a redução deste hormônio poderia ser um dos fatores que explicariam parcialmente os

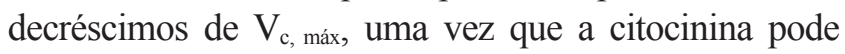
aumentar a síntese de mRNA relacionado à síntese e à atividade da Rubisco e frutose-1,6-bisfosfatase (Davies \& Zhang, 1991).

O aumento de $\mathrm{J}_{\text {máx }}$ em resposta à temperatura $(\mathrm{p}<0,05)$ incrementou a disponibilidade de RuBP para fixação de $\mathrm{CO}_{2}$ e, consequentemente, causou maior consumo de ATP e NADPH, maior $F_{\mathrm{q}}{ }^{\prime} / \mathrm{F}_{\mathrm{m}}{ }^{\prime}$ e ETR, com diminuição da relação ETR/Ag (Figuras 3 C, E, F e 4 B).

Há relação direta entre a temperatura do solo e o crescimento das raízes em citros (Bevington \& Castle, 1985), em que temperaturas abaixo de $13^{\circ} \mathrm{C}$ causam o cessar de crescimento (Reuther, 1977). Com baixa temperatura e baixa demanda por carboidratos, há inibição da mobilização de amido, durante a noite, e redução dos metabolismos de sacarose e nitrogênio nas folhas (Allen \& Ort, 2001), o que causou aumento no teor de carboidratos nas folhas e pode exercer efeito inibitório sobre a fotossíntese (Iglesias et al., 2002). O fluxo de carboidratos para atender demanda exerce efeito sobre a fotossíntese (Ribeiro \& Machado, 2007). Assim, o tratamento em que as raízes foram submetidas à baixa temperatura pode ter causado queda no metabolismo das raízes e na demanda por carboidratos, retrorregulação da fotossíntese e redução de $\mathrm{A}, \mathrm{V}_{c \text {, máx }} \mathrm{e}$ $\mathrm{J}_{\text {máx. }}$ Raízes a $30^{\circ} \mathrm{C}$ demandariam grande quantidade de carboidratos e, possivelmente estimulariam a fotossíntese, o que se refletiria no aumento de $\mathrm{V}_{c \text {, máx }} \in \mathrm{J}_{\text {máx }}$.

\section{Conclusões}

1. A variação da temperatura do substrato, em plantas jovens de laranja 'Valência' enxertadas em limoeiro 'Cravo', afeta a assimilação de $\mathrm{CO}_{2}$, em consequência de fatores difusivos (condutância estomática e do mesofilo) e metabólicos da fotossíntese (eficiência máxima de carboxilação e taxa máxima de regeneração de RuBP).

2. Há relação positiva entre o aumento da temperatura do substrato e o estímulo da assimilação de $\mathrm{CO}_{2}$; todavia, a variação da temperatura não afeta a atividade fotoquímica, e a baixa temperatura das raízes induz o aumento na atividade de drenos alternativos de elétrons.

\section{Agradecimentos}

Ao Conselho Nacional de Desenvolvimento Científico e Tecnológico e à Fundação de Apoio à Pesquisa do Estado de São Paulo, pelo financiamento da pesquisa e pelas concessões de bolsas.

\section{Referências}

ALLEN, D.J.; ORT, D.R. Impacts of chilling temperatures on photosynthesis in warm-climate plants. Trends in Plant Science, v.6, p.36-42, 2001.

BAKER, N.R. Chlorophyll fluorescence: a probe of photosynthesis in vivo. Annual Review of Plant Biology, v.59, p.89-113, 2008.

BERNACCHI, C.J.; SINGSAAS, E.L.; PIMENTEL, C.; PORTIS, A.R.; LONG, S.P. Improved temperature response functions for models of Rubisco-limited photosynthesis. Plant, Cell and Environment, v.24, p.253-259, 2001.

BEVINGTON, K.B.; CASTLE, W.S. Annual root growth pattern of young citrus trees in relation to shoot growth, soil temperature, and soil water content. Journal of the American Society for Horticultural Science, v.110, p.840-845, 1985.

DAVIS, W.J.; ZHANG, J. Root signals and the regulation of growth and development of plants in drying soil. Annual Review of Plant Physiology and Plant Molecular Biology, v.42, p.55-76, 1991.

DEMMIG, B.; BJÖRKMAN, O. Comparison of the effect of excessive light on chlorophyll fluorescence $(77 \mathrm{~K})$ and photon yield of $\mathrm{O}_{2}$ evolution in leaves of higher plants. Planta, v.171, p.171-184, 1987.

DODD, I.C.; HE, J.; TURNBULL, C.G.N.; LEE, S.K.; CRITCHLEY, C. The influence of supra-optimal root-zone temperatures on growth and stomatal conductance in Capsicum annuum L. Journal of Experimental Botany, v.51, p.239-248, 2000 .

EPRON, D.; GODARD, D.; CORNIC, G.; GENTY, B. Limitation of net $\mathrm{CO}_{2}$ assimilation rate by internal resistances to $\mathrm{CO}_{2}$ transfer in the leaves of two tree species (Fagus sylvatica L. and Castanea sativa Mill.). Plant, Cell and Environment, v.18, p.43-51, 1995.

FARQUHAR, G.D.; CAEMMERER, S. von; BERRY, J.A. A biochemical model of photosynthetic $\mathrm{CO}_{2}$ assimilation in leaves of $\mathrm{C}_{3}$ species. Planta, v.149, p.78-90, 1980. 
FLEXAS, J.; RIBAS-CARBÓ, M.; DIAZ-ESPEJO, A.; GALMÉS, J.; MEDRANO, H. Mesophyll conductance to $\mathrm{CO}_{2}$ : current knowledge and future prospects. Plant, Cell and Environment, v.31, p.602-621, 2008.

FNP CONSULTORIA \& COMÉRCIO. Agrianual 2009: anuário da agricultura brasileira. 14.ed. São Paulo: FNP Consultoria \& Comércio, 2009. 497p.

HABERMANN, G.; MACHADO, E.C.; RODRIGUES, J.D.; MEDINA, C.L. Gas exchange rates at different vapor pressure deficits and water relations of 'Pera' sweet orange plants with citrus variegated chlorosis (CVC). Scientia Horticulturae, v.98, p.233-245, 2003.

HUBBARD, R.M.; RYAN, M.G.; STILLER, V.; SPERRY, J.S. Stomatal conductance and photosynthesis vary linearly with plant hydraulic conductance in ponderosa pine. Plant, Cell and Environment, v.24, p.113-121, 2001.

IGLESIAS, D.J.; LLISO, I.; TADEO, F.R.; TALON, M. Regulation of photosynthesis through source: sink imbalance in citrus is mediated by carbohydrate content in leaves. Physiologia Plantarum, v.116, p.563-572, 2002.

KAUFMANN, M.R. Evaluation of pressure chamber method for measurement of water stress in citrus. Proceedings of the American Society for Horticultural Science, v.93, p.186-190, 1968.

LONG, S.P.; BERNACCHI, C.J. Gas exchange measurements, what can they tell us about the underlying limitations to photosynthesis? Procedures and sources of error. Journal of Experimental Botany, v.54, p.2393-2401, 2003.

MACHADO, E.C.; MEDINA, C.L.; GOMES, M. de M. de A.; HABERMANN, G. Variação sazonal da fotossíntese, condutância estomática e potencial da água na folha de laranjeira 'Valência'. Scientia Agricola, v.59, p.53-58, 2002.

MACHADO, E.C.; SCHMIDT, P.T.; MEDINA, C.L.; RIBEIRO, R.V. Respostas da fotossíntese de três espécies de citros a fatores ambientais. Pesquisa Agropecuária Brasileira, v.40, p.1161-1170, 2005.

MAXWELL, K.; JOHNSON, G.N. Chlorophyll fluorescence - a practical guide. Journal of Experimental Botany, v.51, p.659-668, 2000 .
MEDINA, C.L.; SOUZA, R.P.; MACHADO, E.C.; RIBEIRO, R.V.; SILVA, J.A.B. Photosynthetic response of citrus grown under reflective aluminized polypropylene shading nets. Scientia Horticulturae, v.96, p.115-125, 2002.

ORIGINLAB. Origin. Version 7.5. Northampton: OriginLab, 2008.

REUTHER, W. Citrus. In: ALVIM, P. de T.; KOZLOWSKI, T.T. Ecophysiology of tropical crops. New York: Academic, 1977. p.409-439.

RIBEIRO, R.V. Variação sazonal da fotossíntese e relações hídricas de laranjeira 'Valência'. 2006. 157p. Tese (Doutorado) Escola Superior de Agricultura Luiz de Queiroz, Piracicaba.

RIBEIRO, R.V.; MACHADO, E.C. Some aspects of citrus ecophysiology in subtropical climates: re-visiting photosynthesis under natural conditions. Brazilian Journal of Plant Physiology, V.19, p.393-411, 2007.

RIBEIRO, R.V.; MACHADO, E.C.; SANTOS, M.G.; OLIVEIRA, R.F. Seasonal and diurnal changes in photosynthetic limitation of young sweet orange trees. Environmental and Experimental Botany, v.66, p.203-211, 2009.

SCHREIBER, U.; BILGER, W.; HORMANN, H.; NEUBAUER, C. Chlorophyll fluorescence as a diagnostic tool: basics and some aspects of practical relevance. In: RAGHAVENDRA, A.S. Photosynthesis: a comprehensive treatise. Cambridge: Cambridge University, 1998. p.320-336.

TOURNAIRE-ROUX, C.; SUTKA, M.; JAVOT, H.; GOUT, E.; GERBEAU, P.; LUU, D.T.; BLIGNY, R.; MAUREL, C. Cytosolic $\mathrm{pH}$ regulates root water transport during anoxic stress through gating of aquaporins. Nature, v.425, p.393-397, 2003.

WARREN, C.R. Does growth temperature affect the temperature responses of photosynthesis and internal conductance to $\mathrm{CO}_{2}$ ? A test with Eucalyptus regnans. Tree Physiology, v.28, p.11-19, 2008 .

ZHOU, Y.H.; HUANG, L.F.; ZHANG, Y.L.; SHI, K.; YU, J.Q.; NOGUÉS, S. Chill-induced decrease in capacity of RuBP carboxylation and associated $\mathrm{H}_{2} \mathrm{O}_{2}$ accumulation in cucumber leaves are alleviated by grafting onto figleaf gourd. Annals of Botany, v.100, p.839-848, 2007.

Recebido em 7 de junho de 2009 e aprovado em 2 de agosto de 2009 